\title{
Methotrexate in Our Hearts
}
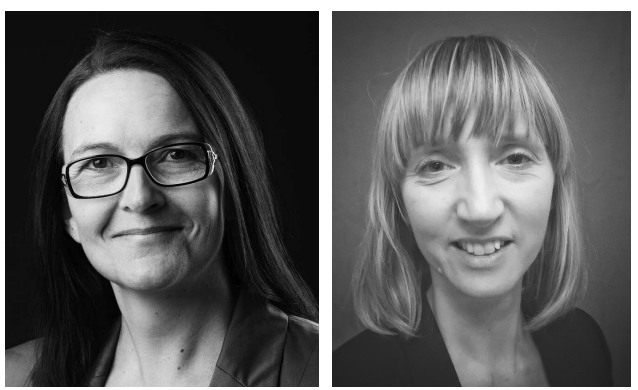

Undoubtedly, methotrexate (MTX) has a unique place in all rheumatologists' hearts. It holds the position of first-line treatment choice for rheumatoid arthritis (RA) in the European and North American treatment guidelines for $\mathrm{RA}^{1,2,3}$. The benefit of early start of disease-modifying antirheumatic drugs (DMARD), where MTX is the most preferred, has been increasingly emphasized in the last decade. In 2010 an expert task force published recommendations aiming at maximizing patients' longterm health-related quality of life, through minimizing disease activity in RA as quickly as possible, with the goals of controlling symptoms, normalizing function, and halting radiographic progression of joint damage ${ }^{4}$. The treatment strategy is widely known as treat to target, and even though it has been questioned ${ }^{5,6}$, it is now a cornerstone in the modern approach to RA disease activity and treatment.

In spite of the strong evidence that the drug is a good first choice for our patients, we still might not use it enough, especially when encountering the onset of RA in the elderly. Patients who develop RA at an older age have higher disease activity and disability, but experience a lesser chance of getting intensive treatment with MTX and other DMARD than their younger counterparts ${ }^{7,8}$.

During the last 20 years we have also become aware that patients with RA have an increased risk of cardiovascular (CV) disease; mainly acute coronary events, but also ischemic stroke. An increased occurrence of traditional risk factors for CV disease does not fully explain the increased risk noted, and it has been suggested that inflammatory activity, and in particular, high disease activity, as seen in active RA, is partly responsible for the risk increase ${ }^{9,10,11}$.

There are several reports indicating a CV risk reduction associated with MTX treatment in RA ${ }^{12,13}$. The underlying mechanisms are largely unknown, but in experimental studies MTX has been observed to inhibit key proatherosclerotic cytokines such as tumor necrosis factor (TNF)- $\alpha$, interleukin (IL)-1, and IL- $6^{14}$. This could result not only in control of the RA disease activity, but also in beneficial effects on endothelial function and vascular homeostasis. Depending on the background for the observed association between disease activity and $\mathrm{CV}$ risk, there are thus several possible explanations for the CV preventive potential of MTX.

No trials have yet been conducted aiming to prove the "inflammatory hypothesis" with MTX treatment in RA. We still await the results from The Cardiovascular Inflammation Reduction Trial, in which patients with a high risk of a second myocardial infarction (but no inflammatory rheumatic disease) were given low-dose MTX or placebo in addition to traditional secondary preventive treatment ${ }^{15}$. In the CANTOS trial ${ }^{16}$, however, treatment with the IL-1 $\beta$ inhibitor canakinumab was shown to lower the inflammation and $\mathrm{CV}$ events in high-risk patients who were free from inflammatory rheumatic disease. Interestingly, it did so without exerting its effect through reduction of blood lipid levels. In RA, there are observational studies on TNF inhibition and its effect on $\mathrm{CV}$ risk, and these studies suggest that it is not the TNF blocking agent per se that reduces the risk of $\mathrm{CV}$ disease. It is rather the effect that TNF blockers have on the disease activity that lowers the risks of $\mathrm{CV}$ disease in RA. In fact, those who lowered their risk the most were patients who responded to TNF treatment, as opposed to those who did not ${ }^{17,18}$. The results of these studies might contribute to the understanding of the role of inflammation on $\mathrm{CV}$ risk in RA.

With this in mind it is interesting to read the study by Widdifield and colleagues in this edition of The Journal ${ }^{19}$. The study includes almost 24,000 patients diagnosed with RA after the age of 65, and the authors' main focus was to assess what effect the actual timing of MTX use has on the risk of $\mathrm{CV}$ disease. This is much needed because most studies on MTX and CV risk have focused on MTX as a binary variable (yes/no treatment with MTX), and have not taken into account when the treatment was given in relation to the $\mathrm{CV}$ event or RA diagnosis. In this cohort of patients diagnosed with RA somewhat later in life than what we usually see in our practices (mean age 75 yrs at diagnosis), only $35 \%$ were treated with MTX within the first year of diagnosis, which is a lot less than what has been reported in

See MTX and CVE in elderly RA, page 467

Personal non-commercial use only. The Journal of Rheumatology Copyright (C) 2019. All rights reserved. 
other cohorts ${ }^{20}$, and the incidence of CV disease was higher than what has been reported previously. Both these aspects of course reflect the fact that the patients were older when diagnosed with RA and when followup started. Nonetheless, what the authors beautifully demonstrate is that the timepoint in their disease history when patients were treated with MTX is important; those treated within the last 12 months were at significantly lower risk of a CV event than those who had not been treated with MTX during the last 12 months. Some of this effect could be due to confounding by indication, an issue the authors address in their discussion, and that perhaps is supported by the lower prevalence of comorbidity noted in the MTX-only group. An additional novelty presented related to timeliness, is that there seemed to be a window of opportunity in $\mathrm{CV}$ risk prevention, not only in the prevention of joint damage, in RA. The patients who were treated with MTX during the first year of diagnosis were also at decreased risk of CV disease compared to those who were not treated, and even though the effect did not last over time and beyond MTX discontinuation, it is an interesting finding. That these patients were older when they were diagnosed than we usually see is another striking aspect. Maybe we should all ask ourselves whether we are denying our older patients the cardioprotective treatment that MTX provides and that the patients need, probably more often than patients diagnosed in their 40s.

The next step in disentangling through what pathway MTX exerts its cardioprotective effect in RA would of course be to assess the effect of MTX in relation to disease activity, and its relation to response to treatment. A clear association between response (compared with a lack of response) to MTX treatment and the risk of CV disease would support the inflammatory hypothesis, and if no association could be detected it would suggest that MTX indeed acts through other pathways than through lowering inflammation when exerting its protective effect.

Regardless, recent MTX treatment and MTX treatment during the first year of RA diagnosis seems to reduce the risk of CV disease in RA. MTX has a well-deserved place as a first-line DMARD. Maybe now is the time to give MTX its rightful place, along with statins and antihypertensives, in $\mathrm{CV}$ prevention in our high-risk patients with RA.

\author{
LOTTA LJUNG (D), MD, PhD, \\ Umeå University, \\ Department of Public Health \\ and Clinical Medicine/Rheumatology, \\ Umeå; and Karolinska Institutet, \\ Department of Medicine Solna, \\ Clinical Epidemiology Division, \\ Stockholm;
}

MARIE HOLMQVIST ${ }^{(D)}$, MD, $\mathrm{PhD}$,

Karolinska Institutet,

Department of Medicine Solna,

Clinical Epidemiology Division, Stockholm, Sweden.
Address correspondence to Dr. M. Holmqvist, Karolinska Institutet, Department of Medicine, Solna, Clinical Epidemiology Division, Eugeniahemmet T2, SE-171 76 Stockholm, Sweden.

E-mail: marie.holmqvist@ki.se

\section{REFERENCES}

1. Smolen JS, Landewé R, Bijlsma J, Burmester G, Chatzidionysiou K, Dougados M, et al. EULAR recommendations for the management of rheumatoid arthritis with synthetic and biological disease-modifying antirheumatic drugs: 2016 update. Ann Rheum Dis 2017;76:960-77.

2. Bykerk VP, Akhavan P, Hazlewood GS, Schieir O, Dooley A, Haraoui B, et al. Canadian Rheumatology Association recommendations for pharmacological management of rheumatoid arthritis with traditional and biologic disease-modifying antirheumatic drugs. J Rheumatol 2012;39:1559-82.

3. Singh JA, Saag KG, Bridges SL, Akl EA, Bannuru RR, Sullivan MC, et al. 2015 American College of Rheumatology guideline for the treatment of rheumatoid arthritis. Arthritis Rheumatol 2016;68:1-26.

4. Solomon DH, Bitton A, Katz JN, Radner H, Brown E, Fraenkel L. Treat to target in rheumatoid arthritis: fact, fiction or hypothesis? Arthritis Rheumatol 2014;66:775-82.

5. Smolen JS, Aletaha D, Bijlsma JW, Breedveld FC, Boumpas D, Burmester G, et al. Treating rheumatoid arthritis to target: recommendations of an international task force. Ann Rheum Dis 2010;69:631-7.

6. Landewé RBM. Overdiagnosis and overtreatment in rheumatology: a little caution is in order. Ann Rheum Dis 2018;77:1394-6.

7. Innala L, Berglin E, Moller B, Ljung L, Smedby T, Sodergren A, et al. Age at onset determines severity and choice of treatment in early rheumatoid arthritis: a prospective study. Arthritis Res Ther 2014;16:R94.

8. Ruban TN, Jacob B, Pope JE, Keystone EC, Bombardier C, Kuriya $B$. The influence of age at disease onset on disease activity and disability: results from the Ontario Best Practices Research Initiative. Clin Rheumatol 2016;35:759-63.

9. Innala L, Möller B, Ljung L, Magnusson S, Smedby T, Södergren A, et al. Cardiovascular events in early RA are a result of inflammatory burden and traditional risk factors: a five year prospective study. Arthritis Res Ther 2011;13:R131.

10. Mantel Ä, Holmqvist M, Nyberg F, Tornling G, Frisell T, Alfredsson $\mathrm{L}$, et al. Risk factors for the rapid increase in risk of acute coronary events in patients with new-onset rheumatoid arthritis: a nested case-control study. Arthritis Rheumatol 2015;67:2845-54.

11. Sattar N, McCarey DW, Capell H, McInnes IB. Explaining how "high-grade" systemic inflammation accelerates vascular risk in rheumatoid arthritis. Circulation 2003;108:2957-63.

12. Roubille C, Richer V, Starnino T, McCourt C, McFarlane A, Fleming $\mathrm{P}$, et al. The effects of tumour necrosis factor inhibitors, methotrexate, non-steroidal anti-inflammatory drugs and corticosteroids on cardiovascular events in rheumatoid arthritis, psoriasis and psoriatic arthritis: a systematic review and meta-analysis. Ann Rheum Dis 2015;74:480-9.

13. Micha R, Imamura F, Wyler von Ballmoos M, Solomon DH, Hernán MA, Ridker PM, et al. Systematic review and meta-analysis of methotrexate use and risk of cardiovascular disease. Am J Cardiol 2011;108:1362-70.

14. Mangoni AA, Zinellu A, Sotgia S, Carru C, Piga M, Erre GL. Protective effects of methotrexate against proatherosclerotic cytokines: a review of the evidence. Mediators Inflamm 2017;2017:11.

15. Everett BM, Pradhan AD, Solomon DH, Paynter N, Macfadyen J, Zaharris E, et al. Rationale and design of the Cardiovascular Inflammation Reduction Trial: a test of the inflammatory hypothesis of atherothrombosis. Am Heart J 2013;166:199-207, e15. 
16. Ridker PM, Everett BM, Thuren T, MacFadyen JG, Chang WH, Ballantyne C, et al; CANTOS Trial Group. Antiinflammatory therapy with canakinumab for atherosclerotic disease. N Engl J Med 2017;377:1119-31.

17. Dixon WG, Watson KD, Lunt M, Hyrich KL, Silman AJ, Symmons DP; British Society for Rheumatology Biologics Register.

Reduction in the incidence of myocardial infarction in patients with rheumatoid arthritis who respond to anti-tumor necrosis factor alpha therapy: results from the British Society for Rheumatology Biologics Register. Arthritis Rheum 2007;56:2905-12.

18. Ljung L, Rantapää-Dahlqvist S, Jacobsson LT, Askling J. Response to biological treatment and subsequent risk of coronary events in rheumatoid arthritis. Ann Rheum Dis 2016;75:2087-94.
19. Widdifield J, Abrahamowicz M, Paterson JM, Huang A, Thorne JC, Pope JE, et al. Associations between methotrexate use and the risk of cardiovascular events in patients with elderly-onset rheumatoid arthritis. J Rheumatol 2019;46:467-74.

20. Holmqvist M, Ljung L, Askling J. Acute coronary syndrome in new-onset rheumatoid arthritis: a population-based nationwide cohort study of time trends in risks and excess risks. Ann Rheum Dis 2017;76:1642-7.

J Rheumatol 2019;46:447-9; doi:10.3899/jrheum.181269 